\section{POR UMA SOCIOLOGIA (AINDA) CRITICA DO ESPORTE NAS AMÉRICAS: O PAPEL DOS INTELECTUAIS E DAS ASSOCIAÇÕES CIENTÍFICAS}

TOWARDS A (STILL) CRITICAL SOCIOLOGY OF SPORT IN THE AMERICAS: THE ROLE OF INTELLECTUALS AND SCIENTIFIC ASSOCIATIONS

POR UNA SOCIOLOGÍA (AÚN) CRÍTICA DEL DEPORTE EN LAS AMÉRICAS: EL PAPEL DE LOS INTELECTUALES Y DE LAS ASOCIACIONES CIENTÍFICAS

Valter Bracht*, Ivan Marcelo Gomes**, Felipe Quintão Almeida***
Esportes.

Intelectuais.

Habermas.

Bauman.

Keywords

Sport. Intellectuals. Habermas.

Bauman.

\section{Palabras clave}

Deportes. Intelectuales. Habermas.

Bauman
Resumo: Este artigo reflete sobre o papel público dos intelectuais. Descreve, para tanto, a posição de dois renomados pensadores da atualidade: Jürgen Habermas e Zygmunt Bauman. Investiga a crise do discurso intelectual de caráter legislador e suas repercussões no papel público da Filosofia e da Sociologia, disciplinas que, respectivamente, esses autores representam. Conclui com implicações para a função pública dos intelectuais que estudam o esporte e suas instituições.

Abstract: This paper reflects upon the public role of intellectuals. In doing so, it draws from the work of two renowned contemporary thinkers, Jürgen Habermas and Zygmunt Bauman. It researches how the "legislator" feature of intellectual discourse has reached a crisis and how this has affected the public role of Philosophy and Sociology, which are represented respectively by the two thinkers. The paper concludes by discussing the implications of these critiques to the public engagement of intellectuals who conduct research on sport and scientific associations.

Resumen: Este artículo reflexiona sobre el papel público de los intelectuales. Describe, para esto, la posición de dos reconocidos pensadores de la actualidad: Jürgen Habermas y Zygmunt Bauman. Investiga la crisis del discurso intelectual de carácter legislador y sus repercusiones en el papel público de la Filosofía y de la Sociología, disciplinas que esos autores, respectivamente, representan. Concluye con implicaciones para la función pública de los intelectuales que estudian el deporte y sus instituciones.
* Departamento de Ginástica. Centro de Educação Física e Desportos da Universidade Federal do Espírito Santo (Cefd/Ufes). Laboratório de Estudos em Educação Física (Lesef). Vitória, ES, Brasil. UFES.

E-mail: valter.bracht@pq.cnpq.br

** Departamento de Ginástica. Centro de Educação Física e Desportos da Universidade Federal do Espírito Santo (Cefd/Ufes). Laboratório de Estudos em Educação Física (Lesef). Vitória, ES, Brasil. UFES.

E-mail: ivanmgomes@hotmail.com

*** Departamento de Ginástica. Centro de Educação Física e Desportos da Universidade Federal do Espírito Santo (Cefd/Ufes). Laboratório de Estudos em Educação Física (Lesef). Vitória, ES, Brasil. UFES.

E-mail: fqalmeida@ hotmail.com

Recebido em: 30-06-2014 Aprovado em: 17-09-2014 (c) (1) (8) Licence 


\section{INTRODUÇÃO}

A Sociologia do Esporte tem um desenvolvimento incipiente no Brasil; aliás, se considerarmos o tempo de vida da Sociologia, a do esporte é recente em todo o mundo. De forma mais sistemática e intensa, ela não é anterior à década de 1960 (RIGAUER, 1982; SOUZA; MARCHI, 2010). Alabarces (1998) afirma que as Ciências Sociais latino-americanas só se preocuparam em produzir discursos explicativos e interpretativos a respeito do esporte avalizados pela comunidade científica no último terço do século passado, embora o esporte moderno já houvesse se tornado um fenômeno com visibilidade social desde o final do século XIX.

Um aspecto peculiar do seu desenvolvimento no Brasil é o de que se deu não só a partir da própria Sociologia, mas também do campo da Educação Física. Aliás, Souza e Marchi (2010) identificaram três vias de desenvolvimento da Sociologia do Esporte em nosso país: a) a via da sociologia do futebol ou, dito de outro modo, estudos socioantropológicos do futebol; ${ }^{1} \mathbf{b}$ ) a via da teoria crítica do esporte, preconizada pelos autores da Educação Física a partir de $1980 ;{ }^{2}$ c) a via da história das práticas esportivas. Valemo-nos dessa análise/classificação para fazer uma primeira demarcação de nosso ensaio, qual seja, tomar como referência e foco de reflexão a segunda trajetória identificada pelos autores. Essa direção de desenvolvimento da Sociologia do Esporte possuiu uma particularidade: trata-se do fato de ter sido, fundamentalmente, uma ferramenta para a crítica do fenômeno esportivo com fins pedagógicos.

Essas observações são importantes ao considerarmos o manifesto de Michael Burawoy, que serviu de inspiração para a chamada desse dossiê, já que alerta para a necessidade de se considerar o contexto em que o conceito de Sociologia Pública foi cunhado. Segundo Burawoy (2006, p. 36):

[...] 0 termo 'Sociologia Pública' é uma invenção americana. Se em outros países essa é a essência da Sociologia, para nós ela não é mais do que uma parte de nossa disciplina, e uma pequena parte. Na verdade, para alguns sociólogos nos Estados Unidos, ela nem pertence a nossa disciplina. Quando eu viajo para a África do Sul, entretanto, para falar sobre Sociologia Pública - e isso seria verdade para muitos países no mundo - minhas audiências me escutam embaraçadas. 0 que mais poderia ser a Sociologia se não um engajamento com públicos diversos sobre questões públicas?

O sentido de desenvolvimento da Sociologia do Esporte no Brasil que tomamos como referência sofre influência, então, dos interesses de um campo profissional de intervenção que é a Educação Física, portanto, de um público específico. Essa disciplina se constitui quando a produção de análises e interpretações sociológicas do esporte passa a ser feita por intelectuais com formação específica em Educação Física que buscaram instrumentalizar-se com conceitos e teorias sociológicas ou sociofilosóficas.

Assim, considerando esse desenvolvimento e o próprio alerta acima mencionado de Burawoy (2006), parece-nos não ser apropriado transferir imediatamente sua classificação (Sociologia Profissional, Sociologia Política, Sociologia Crítica e Sociologia Pública) para o caso da Sociologia no Brasil e, muito menos, para essa via da incipiente Sociologia do Esporte brasileira que se constituiu no campo da Educação Física. 
No seu início, na década de 1980, o caráter crítico (Sociologia Crítica ou Pública, na classificação de Burawoy) dessa via da Sociologia do Esporte no Brasil estava orientado teoricamente por versões do marxismo, por exemplo, o freudo-marxismo de Jean Marie Brohm (1978), divulgado no Brasil inicialmente por Cavalcanti $(1980,1984)$, ou então do marxismo circulante no debate da Educação, mormente o presente na obra de Saviani (1983). Pois bem, o aspecto dessa postura teórica que fundamenta essa versão da Sociologia crítica do esporte que elegemos como foco deste ensaio está relacionado com os critérios de criticidade, suas relações e consequências para o que, agora sim, Burawoy (2006) chama de Sociologia Pública, ou seja, as relações dos intelectuais (da Sociologia) e de sua produção com os diferentes públicos ou com o "público" no sentido amplo do termo. Um dos pontos problemáticos das intervenções de intelectuais na realidade social, sejam eles, por exemplo, sociólogos ou filósofos, tem sido a função e o tipo de autoridade que eles advogam (ou que lhes é atribuído) por ocasião dessa intervenção. Essa "autoridade" adviria da "qualidade" das análises e interpretações desses intelectuais, já que baseadas num fazer "científico" ou "filosófico". Em última instância, trata-se aqui da velha questão do papel político da ciência, da Filosofia ou, mais amplamente, da produção intelectual.

Para problematizar e nos posicionar a respeito dessa relação, trouxemos as considerações de dois intelectuais contemporâneos bastante influentes no campo da Sociologia/Filosofia, que são Jürgen Habermas e Zygmunt Bauman. A eleição desses autores se justifica pela nossa leitura da necessidade de colocar em questão uma postura fortemente presente nessa via da Sociologia crítica do esporte brasileira. Em nossa interpretação, esse posicionamento se sustentou, grosso modo, num "realismo forte" (HABERMAS, 2004) que confere à produção sociológica e a seus intelectuais um caráter "legislador" (BAUMAN, 2010a). Ambos os autores sinalizam para a necessidade ou o fato de o papel dos intelectuais na sociedade contemporânea (entendida como modernidade tardia ou líquida) se configurar ou deixar se caracterizar muito mais pela noção de "interpretação".

Habermas, embora notoriamente conhecido por sua Filosofia, é também sociólogo de "formação". É, assim, um filósofo com forte "sensibilidade" sociológica, aliás, como praticamente toda produção filosófica da chamada "Escola de Frankfurt", onde Habermas inicia sua carreira. Bauman, por sua vez, é sociólogo de "formação" e de "ofício", mas não se furtou a embaralhar as barreiras disciplinares estabelecidas para teorizar sobre a sociedade. Como resultado, são vários os momentos em que recorre aos filósofos para fundamentar suas análises sociológicas, entre os quais se situa o próprio Habermas. Em comum, e malgrado suas diferenças, ambos não abriram mão de problematizar o papel público das especialidades que representam (a Filosofia e a Sociologia, respectivamente) e dos seus intelectuais. Procuramos demonstrar isso a partir da crítica que eles elaboraram ao caráter legislador do discurso intelectual e suas repercussões no papel público da Filosofia e da Sociologia. Após apresentarmos as posições de nossos autores a esse respeito, extraímos, na parte final, implicações para a função pública dos intelectuais que estudam o esporte e suas instituições.

\section{ENTRE A LEGISLAÇÃO E A INTERPRETAÇÃO: A TAREFA PÚBLICA DOS INTELECTUAIS PARA HABERMAS E BAUMAN}

Habermas (2002, 2004), em "sua" história da Filosofia, caracteriza o pensamento metafísico vigente até Hegel como um conceito forte ou substancial de teoria (filosófica). Nesse 
contexto, os filósofos atribuíram a si próprios o papel de juízes ou legisladores supremos não somente em face às ciências, mas também perante a cultura em seu todo. A Filosofia possibilitaria, "[...] aos poucos[,] um acesso privilegiado à verdade, ao passo que o caminho do conhecimento teórico continua inacessível à maioria" (HABERMAS, 2002, p. 42). Com o advento da sociedade moderna, continua Habermas $(2002,2004)$, esse quadro começa a se alterar, pois a Filosofia paulatinamente vai perdendo seu status extraordinário, vendo-se constrangida a abandonar sua pretensão de constituir um acesso privilegiado à verdade. A partir de então, torna-se cada vez mais insustentável sua compreensão no papel de "indicadora de lugar e de juiz" que Ihe foi atribuído (HABERMAS, 2003a). Segundo as palavras do próprio filósofo (2003a, p. 19):

Se renunciarmos à ideia de que o filósofo possa conhecer algo sobre o conhecimento que ninguém mais poderia igualmente conhecer, isso significa que não devemos mais partir da suposição de que sua voz possa ter a pretensão de ser ouvida pelos demais participantes do diálogo como a primeira e última a ser escutada. Significaria igualmente que não acreditamos mais que haja algo como um 'método filosófico' possibilitando ex officio aos filósofos profissionais ter pontos de vista interessantes, por exemplo, sobre a respeitabilidade da psicanálise, a legitimidade das leis duvidosas, a solução de conflitos morais, o 'bem-fundado' das contribuições historiográficas ou críticas literárias e coisas que tais [...].

Essa concepção "extraordinária" de Filosofia foi questionada, ainda segundo Habermas (2002), por desenvolvimentos históricos como: a) o advento, a partir do século XVII, de um novo tipo de racionalidade metódica, com o aparecimento do método experimental das ciências da natureza, com o formalismo na teoria da moral, no direito e nas instituições do Estado de direito; b) o surgimento das ciências históricas e, com elas, uma destranscendentalização dos conceitos tradicionais fundamentais; c) a crítica aos fundamentos de uma filosofia da consciência, o que levou à transição para a filosofia da linguagem. Esses movimentos fizeram cair, por assim dizer, a precedência clássica da Filosofia em frente ao que sempre a ela se opôs: a práxis, pois o clássico primado de uma sobre a outra não "[...] consegue mais resistir às interdependências, que assumem destaque cada vez maior. A inserção das realizações teóricas em seus contextos práticos de formação e de aplicação desperta a consciência para a relevância dos contextos cotidianos de agir e da comunicação" (HABERMAS, 2002, p. 43).

Apesar de reconhecer que a Filosofia jamais poderia assumir para si novamente o papel de árbitro ou legislador supremo, Habermas ainda atribui à sua disciplina (e a seus intelectuais) uma tarefa pública indispensável à democracia, já que, para ele, "A filosofia e a democracia não são apenas do mesmo contexto de origem histórica, mas dependem estruturalmente uma da outra" (HABERMAS, 2004, p. 324). Para Habermas, os filósofos não deveriam se irritar, após Hegel, quando são julgados pelas implicações políticas de suas ideias (HABERMAS, 2002). O efeito público e/ou político do pensamento filosófico, por sua vez, depende da liberdade de pensamento e comunicação das sociedades democráticas, ao mesmo tempo em que o discurso democrático também é dependente da vigilância e intervenção da Filosofia, concebida como uma "[...] guardiã pública da racionalidade" (HABERMAS, 2000, 2003a, 2004), mesmo que esse papel traga cada vez mais aborrecimento e seja isento de privilégios. Para ele, o discurso democrático, sempre ameaçado, "[...] depende da vigilância e intervenção desse guardião público da racionalidade" (HABERMAS, 2004, p. 324). Essa conclusão, identificada em textos mais tardios, já se encontra presente nos anos 1980, na resposta que Habermas (2003a) ofereceu para se contrapor ao que ele próprio denominou de "impressionante crítica da Filosofia": 
[...] R. Rorty desenvolve argumentos metafilosóficos que nos levam a duvidar de que a Filosofia possa de fato desempenhar os papéis de indicador de lugar e do juiz que Ihe foram atribuídos pelo mestre-pensador Kant. Contudo, estou menos convencido da consequêencia que Rorty extrai daí: a afirmação de que a Filosofia, com 0 abandono desses dois papéis, também deva se livrar da tarefa de um 'guardião da racionalidade'. Se entendo bem, o preço que a Filosofia, segundo Rorty, deve pagar por sua recente modéstia é o abandono da pretensão de razão com que o pensamento filosófico veio ele próprio ao mundo. Com a morte da Filosofia deve acabar também a convicção de que a força transcendente que associamos à idéia do verdadeiro ou do incondicional seja uma condição necessária para formas de convivência humanas (HABERMAS, 2003a, p. 19).

Diferente do seu colega Rorty, Habermas acredita que "A filosofia que se limitasse a esclarecer por via hermenêutica o que de qualquer maneira já existe teria posto a perder sua força crítica" (HABERMAS, 2007b, p. 119). A Filosofia, mesmo após a sua crise, ainda ocupa um status particular como mediadora não somente na cultura de outros especialistas, mas também na função fundamental que ela pode exercer para aqueles que habitam o mundo da vida. Para Habermas (2002, 2003a), uma Filosofia tornada pragmática pode funcionar como retaguarda/instância crítica que atua como esclarecedora de conceitos, mediadora de sentido, em suma, intérprete-mediadora voltada para o mundo da vida, responsável pela mediação entre 0 saber dos experts e a prática cotidiana, contribuindo, assim, para que as pessoas tomem conhecimento das deformações presentes no cotidiano. Ela se esforça, ainda hoje, por esclarecer os fundamentos racionais do conhecimento, da linguagem e da ação (HABERMAS, 2004). Segundo as palavras do próprio filósofo (2002, p. 48),

[...] a filosofia move-se no círculo do mundo da vida, numa relação com a totalidade do horizonte fugidio do saber cotidiano. Todavia, ela opõe-se também, e de modo total, ao sadio entendimento humano, através da força subversiva da reflexão, da análise crítica, esclarecedora, fragmentadora. ${ }^{3}$ Devido a esta relação íntima e, ao mesmo tempo, rompida com o mundo da vida, a filosofia se adequa a uma função aquém do sistema com o mundo da vida - ao papel de intérprete, que faz a mediação entre as culturas especializadas da ciência, da técnica, do direito $e$ da moral, de um lado, e a comunicativa cotidiana [...]. ${ }^{4}$

A Filosofia assume essa tarefa, contudo, pressupondo uma consciência falibilista e antifundacionalista. Ela tem consciência de que, afora os questionamentos a respeito do alcance universal de suas pretensões, não tem nada de especial em relação às ciências, menos ainda a certeza de um acesso especial à verdade. Apesar disso, não quer prescindir de realizar "[...] uma promoção iluminadora dos processos de autoentendimento de um mundo da vida referido à totalidade, o qual precisa ser preservado da alienação resultante das intervenções objetivadoras, moralizantes e estetizantes das culturas de especialistas" (HABERMAS, 2002, p. 27). Nesse papel, que possibilita a mediação entre o saber dos especialistas e o cotidiano necessitado de orientação, o filósofo pode contribuir para que as deformações do mundo da vida venham à tona. Isso, todavia, "[...] como instância crítica, porque ela não está mais de posse de uma teoria afirmativa da vida correta" (HABERMAS, 2002, p. 60).

3 Habermas (2002, p. 89) entende que o mundo da vida não atinge o nível de problematização, fugindo "[...] à crítica e à pressão desenvolvida pela surpresa das experiências críticas, porque vive de um adiamento de validez, proporcionado por certezas consentidas preliminarmente, ou seja, por certeza do mundo da vida". O que importa para ele é o papel pragmático de uma verdade bifronte, que serve de intermediária entre a certeza da ação e a assertibilidade discursivamente garantida (HABERMAS, 2004).

4 Para Habermas (2003a), os intérpretes, ao entrarem na comunicação, admitem, por princípio, o mesmo status daqueles cujos proferimentos querem compreender, empenhando-se num processo de crítica recíproca que não permite decidir, a priori, quem aprende de quem. 
A cultura, a sociedade e a pessoa, assim como as esferas privadas e públicas do mundo da vida, são as referências a que a Filosofia deve se reportar em relação às funções que a disciplina pode cumprir nas sociedades contemporâneas. Essa preocupação com as tarefas públicas e/ou políticas da Filosofia e do filósofo é uma marca do trabalho de Habermas, podendo ser encontrada em livros escritos em diferentes momentos da sua trajetória. Por exemplo, está presente no "Excurso sobre o nivelamento da diferença de gênero entre Filosofia e Literatura", contido no "Discurso filosófico da modernidade" (2000), mas também em "Consciência moral e agir comunicativo" (2003a), "Textos e contextos" (1996) e "Verdade e justificação" (2004), livro em que, em seu último capítulo, Habermas sumariza algumas desejáveis tarefas para a Filosofia no que ele chama de tempos pós-metafísicos (mas não pós-filosóficos!). Conforme essa defesa, fica mais fácil compreender por que Habermas entende que a Filosofia poderia ter um efeito eminentemente político, mesmo que esse papel não pressuponha uma fundamentação última para a democracia. Habermas espera que os filósofos, em primeiro lugar, desempenhem a função de intelectuais que participam dos processos públicos

[...] para a autocompreensão das sociedades modernas, calcada no diagnóstico da época. Pois, desde o fim do século XVIII, o discurso da modernidade é conduzido principalmente na forma filosófica de uma autocrítica da razão. Em segundo, a Filosofia pode tornar profícuos sua referência à totalidade e seu plurilingüismo para determinadas interpretações. Como entretém uma íntima relação tanto com as ciências e com o senso comum e compreende as linguagens específicas das culturas de especialistas tão bem quanto a linguagem ordinária enraizada na práxis, ela pode, por exemplo, criticar a colonização de um mundo da vida que é esvaziado pelas intervenções da ciência e da técnica, do mercado e do capital, do direito e da burocracia. Em terceiro, a Filosofia possui por natureza uma competência para responder as perguntas fundamentais da vida em comum normativa, em especial a vida política justa (HABERMAS, 2004, p. 324).

Bauman, por um caminho muito diferente, chega a um diagnóstico bem semelhante ao de Habermas no que diz respeito ao status "extraordinário" do discurso intelectual (o que inclui o filosófico). Essa é uma história que Bauman começa a narrar ainda nos anos 1980, na obra "Legisladores e intérpretes: sobre a modernidade, a pós-modernidade e os intelectuais". Conforme apreendemos nesse livro, o conceito de intelectual moderno extraiu seu significado da memória coletiva da "llustração" europeia. O projeto da "República das letras", ditado pela suprema e inquestionável autoridade da razão, fornecia os critérios para avaliar a sociedade, indicando "o que" e "como fazer" para se levar uma vida "reta", sem desvios. Argumenta Bauman que a razão filosófica não podia ser senão um poder prescritivo, sendo os filósofos as pessoas dotadas com acesso mais direto à razão genuína, liberta dos interesses estreitos. Sua tarefa seria descobrir que tipo de comportamento a razão ditaria à pessoa comum, sem o qual a felicidade do povo jamais seria alcançada. Essa razão filosófica, conforme sua descrição, era qualquer coisa, menos contemplativa; não bastava a ela interpretar o mundo, era preciso transformá-lo; e os filósofos, únicos Verdadeiramente dotados da Razão, tinham a resposta para isso (ALMEIDA; GOMES; BRACHT, 2009).

Essa leitura do papel do intelectual é inseparável do diagnóstico de Bauman a respeito da modernidade. As metáforas da "ordem" e da "solidez" são costumeiramente por ele utilizadas para se referir a ela (BAUMAN, 1998a, 1999, 2001, 2010a). A modernidade fez da "ordem como tarefa" o paradigma de seu funcionamento, derretendo os "sólidos" (as tradições, o senso comum etc.) que encontrava em seu caminho na perspectiva de construir outros, mais 
"duráveis" e conforme o modelo de sociedade planejado a partir da inquestionável autoridade dos legisladores modernos, entre os quais os próprios filósofos e, claro, o Estado. ${ }^{5}$ Segundo Bauman, o mundo racional e universal da ordem e da solidez era compatível com a contingência e com a ambivalência. Paradoxalmente, porém, o impulso para sínteses universalizadoras ou consensuais (que estavam na base do projeto de ordem como tarefa da modernidade) resultou sempre mais em bifurcações intermináveis, em novas separações e múltiplas divisões. Em outras palavras, o impulso para a ordem dotada de um propósito retirou toda sua energia do horror à ambivalência, porém foi mais ambivalente o produto final dos impulsos modernos para a ordem.

Assim descrita a história da modernidade, Bauman dirá que a estratégia moderna do trabalho intelectual é mais bem caracterizada pela metáfora do papel de "legislador". Aos intelectuais competia a tarefa de fazer afirmações de autoridade que arbitram em controvérsias de opiniões e escolhas que, após selecionadas, passam a ser corretas. Como são dotados de um conhecimento "superior" e mais "objetivo", os postulados que se destinam aos "outros" (ao povo, ao cidadão comum) vêm na forma heterônoma da lei ou da norma moral. Nessas circunstâncias, há a imposição da perspectiva que se julga em melhores condições de acessar as regras procedimentais que asseguram a conquista da verdade, do juízo moral válido e da seleção de um gosto mais apropriado.

Essa descrição da modernidade, como a marcha do erro para a verdade, do caos para a ordem e da insensatez para o império da razão, está "desacreditada" no habitat pós-moderno, ${ }^{6}$ que adquiriu a capacidade de "[...] 'estar à vontade com uma multiplicidade de diferentes espécies de pessoas' e avançando em direção a uma unicidade em que 'ninguém julga possível pensar que Deus, ou a verdade, ou a natureza das Coisas, está do seu lado'" (BAUMAN, 1998b, p. 149). Porque a pluralidade de verdades deixou de ser um irritante temporário e pela possibilidade de diferentes opiniões poderem ser não apenas simultaneamente julgadas verdadeiras, mas, de fato, simultaneamente verdadeiras, continua Bauman (1998b), a tarefa da razão filosófica deslocou-se da função de legislar acerca do modo correto de separar a verdade da inverdade para a de interpretar acerca do modo correto de traduzir entre línguas distintas, cada uma gerando e sustentando suas próprias verdades. Tal estratégia, segundo Bauman (2010a) a irá conceber, abandona abertamente o suposto da universalidade da verdade, do juízo moral e do gosto e, com ele, a prolongada adesão a discursos legitimadores e fundacionais de toda ordem. De acordo com as palavras do próprio Bauman (2010a, p. 20-21),

A estratégia pós-moderna de trabalho intelectual é aquela mais bem caracterizada pela metáfora do papel de 'intérprete'. Consiste em traduzir afirmações feitas no interior de uma tradição baseada em termos comunais, a fim de que sejam compreendidas no interior de um sistema de conhecimentos fundamentado em outra tradição. Em vez de orientar-se para selecionar a melhor ordem social, essa estratégia objetiva facilitar a comunicação entre os participantes autônomos (soberanos). Preocupa-se em impedir distorções de significado no processo de comunicação. Para este fim, promove a necessidade de penetrar em profundidade 0 sistema estrangeiro de conhecimento do qual a tradução deve ser feita.

\footnotetext{
5 Na leitura de Bauman (2010a), o Estado moderno é do tipo jardineiro: limpa o "lugar" em nome do novo, de plantas cultivadas com cuidado e previamente selecionadas. Sua função é eliminar as "culturas silvestres", povoadas de ervas daninhas, substituindo-as por uma "cultura de jardim".

6 Em Bauman, pós-moderno não é sinônimo de fim da modernidade. A esse respeito, ver o próprio Bauman (2010a) ou Almeida, Gomes e Bracht (2009).
} 
O bom intérprete é aquele que, ao mediar a comunicação entre "províncias finitas" ou "comunidades de significado", consegue ler a mensagem de maneira adequada, sem que, para isso, precise de alguém ou de uma instância legisladora ou legitimadora que separe as boas interpretações das ruins. Nesse contexto, por sua vez, "[...] a Sociologia é mais necessária do que nunca [...]" (BAUMAN, 2001, p. 241). Seu problema prático a resolver "[...] é 0 esclarecimento que tem por objetivo a compreensão humana" (BAUMAN, 2001, p. 241). Isso não quer dizer que a Sociologia tenha o monopólio da sabedoria em relação às experiências humanas; afinal, isso não faz mais sentido após a "queda do legislador" (BAUMAN, 2010a), mas o entendimento relacional-interpretativo que a Sociologia produz tem o poder de nos iluminar os meios pelos quais conduzimos o mundo da vida, ao lançar luz sobre o que, de outra maneira, poderia passar despercebido no curso dos acontecimentos diários. O sociólogo, portanto, tem a tarefa de oferecer uma interpretação das experiências cotidianas por meio de processo de entendimento e de explicação. Segundo, agora, as palavras do próprio Bauman (2010b, p. 265),

Caracterizemos a Sociologia como um comentário da vida social. Ao fornecer uma série de notas explicativas às nossas experiências, ela também mostra implicações para a maneira como conduzimos nossa vida. Atua, assim, como meio para refinar o conhecimento que temos e empregamos em nosso dia a dia, trazendo à luz, além de nossas relações, as coerções e possibilidades enfrentadas, relacionando nossas ações às posições e condições em que nos encontramos. A Sociologia é um olhar disciplinado que analisa 'como' procedemos em nossa vida cotidiana e aloca os detalhes oriundos dessa análise em um 'mapa' que se estende para além de nossas experiências imediatas.

Bauman (2010b) defende que o saber sociológico tem algo a oferecer que o senso comum, por mais rico que seja, sozinho não pode nos dar. Ele coloca em questão aquilo que é considerado inquestionável, abalando as certezas da vida e fazendo aquelas perguntas que não fazemos e, quando as expomos, provocam ressentimento entre os que detêm os interesses estabelecidos. Engana-se, contudo, quem avalia que o tipo de serviço intelectual que a Sociologia pode cumprir resume-se a oferecer "conselhos" aos habitantes da sociedade atual. Aliás, nossa sociedade está saturada de especialistas que oferecem seus conhecimentos para que as pessoas, sozinhas, lidem com as pressões de uma sociedade desregulamentada, privatizante e incerta. Esses "conselhos", normalmente, dirigem-se à esfera privada, ao âmbito daquilo que Bauman (2001), parafraseando Giddens, chama de "política-vida".

Assim concebida a tarefa da Sociologia, a crítica que pode desempenhar é "desdentada", na medida em que não esclarece o abismo que se abriu entre o direito à autoafirmação individual e a capacidade de controlar as situações sociais que podem tornar essa autoafirmação algo factível ou irrealista. Esse hiato, principal contradição da modernidade atual (que Bauman gosta de adjetivar de líquida), não pode ser transposto apenas pelos esforços individuais, mas é

[...] tarefa da Política com P maiúsculo. Pode-se supor que o abismo em questão emergiu e cresceu precisamente por causa do esvaziamento do espaço público, e particularmente da ágora, aquele lugar intermediário, público/privado, onde a política-vida encontra a Política com $\mathrm{P}$ maiúsculo, onde os problemas privados são traduzidos para a linguagem das questões públicas e soluções públicas para os problemas privados são buscadas, negociadas e acordadas (BAUMAN, 2001, p. 49). 
A tarefa na ordem do dia do discurso intelectual, portanto, é fazer a ágora retomar o político. ${ }^{7}$ Essa tarefa é das mais urgentes, pois, por um lado, a sociedade atual experimenta a crescente separação entre o poder extraterritorial do capital e a política, cujas instituições continuam locais; como consequência, as pressões do mercado estão substituindo a legislação política. Por outro lado, a esfera pública está sendo colonizada pela privada, ao mesmo tempo em que o espaço público se transformou no lugar onde se faz a confissão dos segredos e sentimentos privados (quanto mais íntimos melhor) - em vez de ser o espaço para encontro e diálogo sobre problemas privados e questões públicas (BAUMAN, 2000, 2001). A função esclarecedora da Sociologia consiste, portanto, em problematizar a separação entre poder e política, a privatização e a despolitização da esfera pública, "[...] ainda que, paradoxalmente, não para reduzir, mas para viabilizar a liberdade individual" (BAUMAN, 2001, p. 62).

\section{CONSIDERAÇÕES FINAIS}

Parte importante da Sociologia do Esporte no Brasil, especialmente em sua versão crítica, está ancorada no campo da Educação Física, orientando os questionamentos dirigidos ao esporte quando o que está em jogo é sua relação com a Educação Física escolar. Seu nascedouro foi caracterizado por apresentar uma perspectiva crítica, tendendo ou, pelo menos, mais próxima, ao que Bauman caracteriza como uma postura legisladora ou Habermas nomeia como uma instância "indicadora de lugar e de juiz", muito em função de suas vinculações teóricas e de sua relação com uma pedagogia normativa. Uma parte dos intelectuais da Educação Física que fizeram a crítica ao esporte (nos anos 1980), investidos da "razão", da "verdade histórica" e de um novo "projeto de ordem" para o campo, assumiu o compromisso de desvelar aos professores o caminho que os levaria à "verdadeira Educação Física", o que pressupunha uma nova maneira de situar o esporte em seu interior. A autoridade daqueles intelectuais para arbitrar entre o "certo" e o "errado", o "verdadeiro" e o "falso", o "ideológico" do "não ideológico" estava fundamentada no acesso que possuíam a um conhecimento (objetivo) superior ao qual a parte não intelectual - os professores das escolas - não tinha acesso (ou melhor, tinha acesso apenas em sua dimensão ideológica, já parcial). Essa postura, além disso, parece presumir que há uma verdadeira forma da prática esportiva, aquela que não seria ideológica, alienada ou coisificada, mas que, em sua essência, seria formativa, emancipadora ou libertadora e a função do intelectual crítico seria retirar o véu da aparência.

Segundo nossos autores, os desenvolvimentos contemporâneos levaram a um questionamento dos pressupostos que fundamentavam essa postura em favor de uma "consciência falibilista e antifundacionalista". Essa é uma perspectiva mais afeita à noção, compartilhada por Habermas e Bauman, do intelectual como um intérprete, cujo propósito é facilitar a comunicação entre os participantes autônomos na expectativa de impedir distorções de significado na conversação. Nesse processo, os intelectuais, como intérpretes-tradutores, podem colaborar para a autocompreensão das sociedades atuais, trazendo à tona as deformações que o sistema esportivo produz no mundo da vida e, ao mesmo tempo, mediando o que se passa no

\footnotetext{
7 Para Bauman (2000, p. 92-93), "A distinção entre as esferas pública e privada é antiga, remonta aos ambientes doméstico [oikos] e político [eclésia] grego, este o local em que os assuntos concernentes a todos os membros da pólis eram discutidos e resolvidos. Mas entre oikos e eclésia os gregos situavam um outra esfera, a da comunicação entre as outras duas: a esfera cujo papel principal não era manter o público e o privado separados nem preservar a integridade territorial de cada um, mas garantir um tráfego suave e contínuo entre eles. Essa terceira esfera intermediária, a ágora [esfera pública/privada, como define Castoriadis), une e mantém juntos os dois extremos. Seu papel crucial para a manutenção de uma pólis verdadeiramente autônoma que se apoiava na verdadeira autonomia dos seus membros. Sem a ágora nem a pólis nem seus membros poderiam alcançar e muito menos preservar a liberdade de decidir o sentido do bem comum e o que se deveria fazer para atingi-lo".
} 
âmbito das culturas especializadas (entre elas, a dos estudiosos do esporte) para o público não profissional que está inserido na prática comunicativa cotidiana.

Então, isso significa abdicar da tarefa "crítica"? Entendemos que não, pois os intelectuais continuariam com sua função esclarecedora ou iluminadora do cotidiano, problematizando no senso comum as certezas corriqueiras do esporte. Fazem isso, todavia, sem a pretensão de ser um "discurso extraordinário" ou "legislador", mas, muito antes, indica uma necessária reorientação da crítica no sentido de aumentar a importância da construção de espaços públicos onde os intelectuais críticos devem comparecer para apresentar e debater suas interpretações não convencionais e não comuns do fenômeno esportivo e, assim, participar e enriquecer o "jogo democrático".

A partir de um entendimento processual de verdade, é fundamental que esses espaços para diferentes públicos sejam gerados e ocupados na perspectiva do debate amplo, em que não pode ser definido, a priori, "quem aprende de quem" (HABERMAS, 2003a). Daí, por exemplo, a importância da existência de meios de comunicação públicos (não estatais) e de demais instituições públicas para evitar que os interesses mercadológicos sejam definidores da agenda, do resultado e das condições do debate público também no campo do esporte. A tarefa de uma Sociologia crítica do esporte passa por evitar essa colonização.

Como exemplo de uma possível instituição pública, gostaríamos de trazer o caso do Colégio Brasileiro de Ciências do Esporte (CBCE), espaço que, dadas as condições objetivas, é tão impossível quanto necessário.

No desenvolvimento do movimento crítico da Educação Física citado na introdução, em cujo bojo se desenvolve uma incipiente Sociologia do Esporte, essa entidade acadêmica (associação privada, sem fins lucrativos) foi um ator político fundamental, já que exerceu o papel de articuladora e construtora de fóruns de discussão e veículos de disseminação (publicização) de interpretações (autodeclaradas "críticas") do fenômeno esportivo. Seu público sempre foi constituído, basicamente, da comunidade da Educação Física: professores do ensino superior (acadêmicos), professores do ensino fundamental e médio, profissionais atuantes em outras instâncias onde as práticas esportivas estavam presentes, bem como estudantes de Educação Física. Embora criticada por alguns setores como entidade indevidamente "politizada" (pelo menos a partir de 1985, quando segmentos importantes do "movimento renovador" da Educação Física passam a dar a direção da entidade), ${ }^{8}$ essa associação procurou oferecer um espaço público para a manifestação de diferentes interpretações acerca do fenômeno esportivo.

Podemos citar como exemplo um tema absolutamente atual, qual seja, o da realização dos chamados megaeventos esportivos no Brasil (Copa do Mundo de Futebol em 2014 e Jogos Olímpicos de Verão em 2016). As diferentes instâncias do CBCE, particularmente seus congressos, ${ }^{9}$ têm feito dos megaeventos um constante tema, na perspectiva de aprofundar a discussão sobre as suas possíveis repercussões na Educação Física, no esporte e na sociedade de maneira geral. Foi em grande parte graças a essa esfera pública (concretizada em inúmeros congressos e publicações) que interpretações que contrariavam interesses econômicos e políticos puderam chegar ao seu público-alvo. Isso porque os megaeventos esportivos, no Brasil, são exemplares do modo como as pressões do mercado (esportivo) substituem ou

8 Essas disputas no interior do CBCE estão devidamente registradas e analisadas em Paiva (1994) e Damasceno (2013).

9 O último Congresso Brasileiro de Ciências do Esporte/Congresso Internacional de Ciências do Esporte, sediado em Brasília, no ano de 
enfraquecem a legislação política, do modo como a esfera pública é colonizada pela esfera privada, tudo em favor do alardeado "padrão Fifa". O CBCE e os intelectuais que o frequentam têm exercido o papel de esclarecer os poderosos interesses econômicos da Fifa e de seus patrocinadores e como eles se contrapõem aos interesses do povo brasileiro que, em princípio, deveriam ser defendidos pelo Estado. Historicamente, aliás, o CBCE tem assumido a tarefa de problematizar o caráter salvacionista do esporte (o esporte é saúde, o esporte é educação, panaceia para todos os problemas da sociedade) e, recentemente, dos legados dos megaeventos para o país-sede. Tem funcionado, assim, como uma espécie de "guardião público" ao denunciar a "racionalidade" que sustenta a realização dos megaeventos e que tem levado, inexoravelmente, à privatização e despolitização de sua agenda.

Essas preocupações estiveram presentes na entidade antes mesmo ${ }^{10}$ do aparecimento de um desejo e um clamor mais generalizado na sociedade brasileira de discutir, mais radicalmente, como os megaeventos vão repercutir na vida do povo brasileiro, sem falar, é claro, nas inúmeras denúncias de malversação de dinheiro público envolvendo a sua realização. Não foi possível identificar, nos fóruns específicos das Ciências Sociais, um destaque equivalente a essa questão (por exemplo, no 38ํㅡㄹ Encontro Anual da Associação Nacional de Pós-Graduação em Ciências Sociais, em 2014, não foi possível identificar nenhuma mesa-redonda, entre as 22 programadas, que discutisse o tema ou mesmo que o tangenciasse); tampouco um Grupo de Trabalho (GT) específico colocou o tema em pauta. Há, obviamente, exceções, como o caso do dossiê da revista "Horizontes Antropológicos", da UFRGS (ano 19, n. 40), publicada em 2013 e dedicada aos megaeventos esportivos.

Aqui vale uma rápida interlocução com dois aspectos ressaltados por Burawoy (2006): o primeiro diz respeito aos cuidados que precisam ser tomados quanto ao engajamento político das associações científicas (no caso do autor, da American Sociological Association - ASA) e, em nosso caso, do CBCE. Falar em nome de todos os membros ou associados é sempre difícil e perigoso. Para isso é preciso construir mecanismos internos de debate para que a diversidade inerente a essas associações não seja aplainada a partir da posição de um grupo ou dos seus dirigentes. $\mathrm{O}$ segundo aspecto diz respeito ao risco do cientificismo, ou seja, dos cientistas darem as costas para a realidade social em favor do seu próprio curriculum vitae ou, como no caso brasileiro, do "Lattes". O CBCE e seus integrantes precisam manter sempre aberta a busca de interpretações rigorosas que não se limitem aos apelos mercantis e ao fornecimento de conselhos para a política-vida; nem mesmo deveria servir como braço partidário que interpreta o esporte a partir das conveniências políticas do momento. $O$ espaço público produzido pelo CBCE pode constituir-se num espaço onde vozes dissonantes e que resistem as esses processos podem se manifestar e encontrar eco.

Retornando ao plano mais propriamente epistemológico, entendemos que o desafio da Sociologia Pública e crítica nesse âmbito é sustentar (ou renovar) a perspectiva crítica em tempos pós-metafísicos, antifundacionalistas e desconstrucionistas. Onde ancorar a teoria crítica? Como sustentar sua normatividade? As respostas de Habermas e Bauman, em suas diferenças, levam-nos à necessidade de preservação e construção de novos e ampliados espaços públicos, o que equivale a conduzir a um "empoderamento" da política diante do mercado e a um recrudescimento do debate democrático livre de qualquer constrangimento, a não ser a força do melhor argumento.

10 A mídia mais "independente", claro, também já atuava na direção da denúncia e da problematização dos legados dos megaeventos para o País. 


\section{REFERÊNCIAS}

ALABARCES, P. ¿ De qué hablamos cuando hablamos de deporte?. Revista Nueva Sociedad, Caracas, n. 154, p. 74-86, 1998.

ALMEIDA, F. Q.; GOMES, I. M.; BRACHT, V. Bauman e a educação. Belo Horizonte: Autêntica, 2009.

BAUMAN, Z. Modernidade e holocausto. Rio de Janeiro: Jorge Zahar, 1998a.

BAUMAN, Z. 0 mal-estar da pós-modernidade. Rio de Janeiro: Jorge Zahar, 1998b.

BAUMAN, Z. Modernidade e ambivalência. Rio de Janeiro: Jorge Zahar, 1999.

BAUMAN, Z. Em busca da política. Rio de Janeiro: Jorge Zahar, 2000.

BAUMAN, Z. Modernidade líquida. Rio de Janeiro: Jorge Zahar, 2001.

BAUMAN, Z . Legisladores e intérpretes: sobre a modernidade, a pós-modernidade e os intelectuais. Rio de Janeiro: Jorge Zahar, 2010a.

BAUMAN, Z _. Aprendendo a pensar com a sociologia. Rio de Janeiro: Jorge Zahar, 2010b.

BROHM, J. M. Deporte, cultura y represión. Barcelona: Gustavo Gili, 1978.

BURAWOY, M. Por uma sociologia pública. Política \& Trabalho, João Pessoa, n. 25, p. 9-50, out. 2006.

CAVALCANTI, K. B. Característica do esporte na sociedade industrial. Boletim de Intercâmbio, Rio de Janeiro, n. 2, p. 17-22, abr./jun. 1980.

CAVALCANTI, K. B.. Esporte para todos: um discurso ideológico. São Paulo: Ibrasa, 1984.

DAMASCENO, L. G. A educação física na formação do Colégio Brasileiro de Ciências do Esporte. Campinas: Papirus, 2013.

HABERMAS, J. Textos y contextos. Barcelona: Ariel, 1996.

HABERMAS, J. 0 discurso filosófico da modernidade. São Paulo: Martins Fonte, 2000.

HABERMAS, J. Pensamento pós-metafísico. Rio de Janeiro: Tempo Brasileiro, 2002.

HABERMAS, J. Consciência moral e agir comunicativo. Rio de Janeiro: Tempo Brasileiro, 2003a.

HABERMAS, J. Mudança estrutural da esfera pública: investigações quanto a uma categoria da sociedade burguesa. Rio de Janeiro: Tempo Brasileiro, 2003b.

HABERMAS, J. Verdade e justificação: ensaios filosóficos. São Paulo: Loyola, 2004.

LOPES, J. S. L. Futebol 'mestiço': história de sucessos e contradições. Revista Ciência Hoje, Rio de Janeiro, v. 24, n. 139, p.18-26, 1998.

PAIVA, F. S. L. Ciência e poder simbólico no Colégio Brasileiro de Ciências do Esporte. Vitória: Ediufes, 1994.

RIGAUER, B. Sportsoziologie. Hamburg: Rowohlt, 1982.

SAVIANI, D. Escola e democracia. São Paulo: Autores Associados, 1983.

TORRI, D.; VAZ, A. F. Do centro à periferia: sobre a presença da teoria crítica do esporte no Brasil.

Revista Brasileira de Ciências do Esporte, Campinas, v. 28, n. 1, p. 185-200, 2006. 